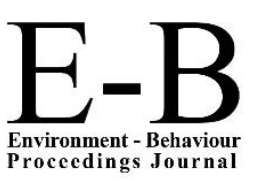

\title{
AicE-Bs2015Barcelona
}

$6^{\text {th }}$ Asia-Pacific International Conference on Environment-Behaviour Studies,

Barcelona School of Architecture (ETSAB), Barcelona, Spain,31 Aug.- 05 Sep. 2015

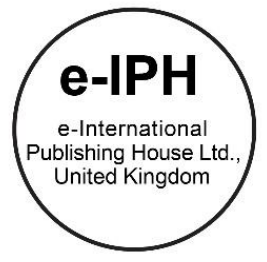

\section{Promotion of Inclusive Society through Therapeutic Sensory Stimulation Garden for the Intergenerational Society}

\author{
Hazreena Hussein ${ }^{1 *}$, Syaidatul Azzreen Ishak, Zaliha Omar² \\ 1 University of Malaya, Faculty of Built Environment, Department of Architecture, Kuala Lumpur 50603, Malaysia \\ 2 University of Malaya Medical Centre, Malaysian Association of Rehabilitation Physicians, Kuala Lumpur, Malaysia
}

\begin{abstract}
This paper introduces a joint program between the University of Malaya and Kuala Lumpur City Hall undertaking the Therapeutic Sensory Stimulation Garden at University of Malaya Medical Centre to promote an inclusive society through sensory therapy. Good universal design practices of sensory gardens visited in the UK, Singapore and Hong Kong highlighted. Outcomes showed that users' engagement with the landscape features promotes positive developments in social behaviours. In contrary, it proved a weak partnership between practitioners, researchers, authorities and users as well as non-availability of design guidelines for these gardens. Both outcomes are a significant argument in the conclusion.

(c) 2016. The Authors. Published for AMER ABRA by e-International Publishing House, Ltd., UK. Peer-review under responsibility of AMER (Association of Malaysian Environment-Behaviour Researchers), ABRA (Association of Behavioural Researchers on Asians) and cE-Bs (Centre for Environment-Behaviour Studies, Faculty of Architecture, Planning \& Surveying, Universiti Teknologi MARA, Malaysia.
\end{abstract}

Keywords: Inclusive society; intergenerational society; sensory garden; universal design.

\section{Introduction}

Research into sensory gardens is relatively new in the Malaysian context. An extensive investigation carried out by Hussein (2009a) looked into the design and use of sensory gardens in the United Kingdom. Hussein (2011, 2010a, 2010b) was evaluated how users engaged with the landscape features that influence their social behaviours. She pioneered sensory environments at a local university in partnership with a local practitioner in Malaysia on the challenges of engaging research. Additionally, practice in the Malaysian and British context (Hussein, Nik Zainal Abidin and Omar, 2013a). Her current involvement in a Grand Challenge Program: Universal Design and Inclusive Society for Kuala Lumpur Built Environment is a three-year collaborative program involving the University of Malaya with Kuala Lumpur City Hall (KLCH). The Grand Challenge Program gives priority to research-based community service. This Program creates the way for representatives from government agencies and authorities together with independent stakeholders to meet, discuss, debate, create solutions, designs and policies as well as share best practices for the issues identified. There are four subject areas that encompass all aspects of life: Universal design

\footnotetext{
* Corresponding author. Tel.: +0-000-000-0000

E-mail address: reenalambina@um.edu.my
} 
for seamless transportation and mobility; Fully accessible public facilities building; Enhancing well-being through recreational and sensory therapy in landscape design; and Universally designed tourism industry.

This paper emphasizes the third subject area: Enhancing Well-Being through Recreational and Sensory Therapy in Landscape Design. In this sub-area, professional inputs by a Rehabilitation Physician, a Research Expert in environmentbehaviour interactions and a Landscape Designer lead to the integration of a sensory landscape to a community building for the intergenerational society. A study at the Therapeutic Sensory Stimulation Garden (TSSG) in University of Malaya Medical Centre (UMMC), Kuala Lumpur is undertaken. The Garden had its soft launch in October 2014 with an aim to practice the universal design of the built environment that will benefit the intergenerational society in terms of research and academic knowledge. The objectives are to introduce therapeutic sensory stimulation garden in Kuala Lumpur's green spaces and to promote universal design, inclusive society, and well-being awareness through recreational and sensory therapy. Besides findings from case studies in the UK (Hussein, 2015a; 2013b; 2010c; 2009b; 2009c) this paper also highlights good universal design practices of sensory gardens recently visited in Singapore and Hong Kong. KLCH will be a precedent to other local authorities that will be emulated by others in different cities and towns of Malaysia once the guideline of integrating a sensory garden concept is established. Working with the Landscape and Urban Design departments in $\mathrm{KLCH}$, a pilot project implemented will be an excellent case study.

\section{Literature Review}

The living environments of modern day children and adolescents have changed rapidly by media innovations and substance abuse. (Macoveia, et. al, 2014). These issues have affected social behavior through the lack of outdoor areas for leisure and communication with peers, as part of the social development of human being (lulian-Dorua \& Maria, 2013). Parents and teachers often see children being outdoors as unsafe (Bruyere, 2011) and unhealthy due to the polluted environment (Louv, 2013) are the problems that have been arising. Hence, the framework such as "Optimal Healing Environment" (OHE) play the role of the physical environment towards the establishment of healing environment (Ghazali R. \& Abbas M.Y., 2012). A welldesigned supportive environment such as a playground and recreational park can reduce those challenging practices (Chaudhury, et. al, 2013). Besides, it can verify personality deviations in a certain length of time (Harun M. T \& Salamuddin N., 2010). Melville \& Bernard (2011) stated that intergenerational programming is one way of associating the generational divide and building more interconnected communities. So what is the way forward in promoting the intergenerational society? According to Detweiler et al. (2012), "healing gardens" or "therapeutic gardens" offer space for physical movements, gardening activities and approximation with nature (Vries, 2010). The term "sensory garden", explains the sensory landscapes that are designed to accommodate the visually impaired, low mobility groups, aged or weak minded (Phillips and Butler, 2011). For the purpose of this paper, the term "therapeutic sensory stimulation garden" is used to illustrate sensory stimulation, therapeutic and healing values of a garden for an intergenerational society. Senses that are stimulated refer to sight, hearing, smell, taste, touch, emotional and spiritual.

\section{Methodology}

Hussein and Daud's recent discussion (2015b) on methods for conducting empirical work with individual needs users and their adult carers is useful concerning this research. This research employed a combination of methods to understand the engagement of users with the garden features and their behaviours when experiencing the case study sensory garden. The first stage of data collection was preliminary site observations, mainly carrying out personal observations of the use of TSSG. It provided insight into the major issues about the site. This fieldwork would further help in the preparation of interviews and focus group discussions at the subsequent data collection stage. The second phase involved walk-through interviews with a diverse group of end users to enquire about their experience with, problems and benefits in using the sensory garden. They comprise of a speech therapist, a nurse, eight occupational therapists, six physiotherapists, three public users, two wheelchair users and two adult carers. Subsequently, focus group discussion with design practitioners in collaboration with the Malaysian Information Network on Disabilities (MIND) was conducted. It is to discuss the challenges they had to deal with in planning, developing and managing green spaces in Malaysia. There are two research limitations in the methodology. Firstly, the number of end users, particularly patients of the hospital was limited due to their schedule of activities. Secondly, in the focus group discussion with practitioners, only landscape architects and architects attended the session. It would be interesting to have views from urban planners. 


\section{Findings}

TSSG located on the 6th floor of the South Tower, UMMC in Kuala Lumpur. There are two entries: one from the fire escape stairs and another from the escalators, see Fig 1. The Garden is not intentionally open to the public. Based on a timetable, patients are accompanied by the hospital staffs for the rehabilitation activity session, which start from 8 am to 4 pm, Monday to Friday. Among garden features available are a mural wall, seating, reflexology path, textured and sound artifacts. Also pergola with climbers, herbs, medicinal and scented plants in raised beds and water feature with marginal plants, see Fig 2.

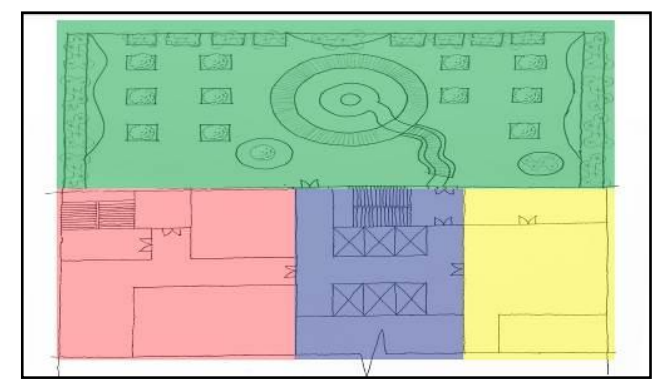

Fig.1. TSSG's site context. Legend: Zone A (TSSG), Zone B (Ward), Zone C (Elevator), Zone D (Endoscopy Unit)

a

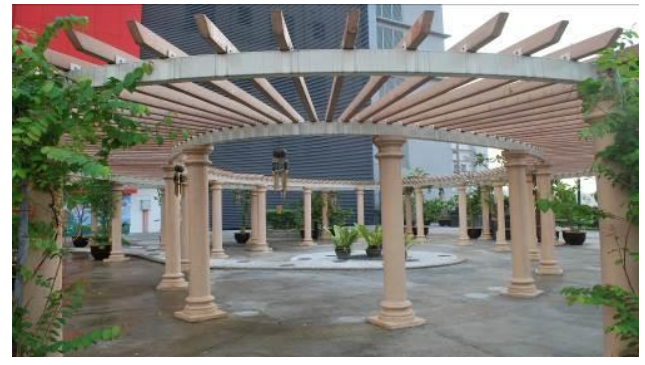

b

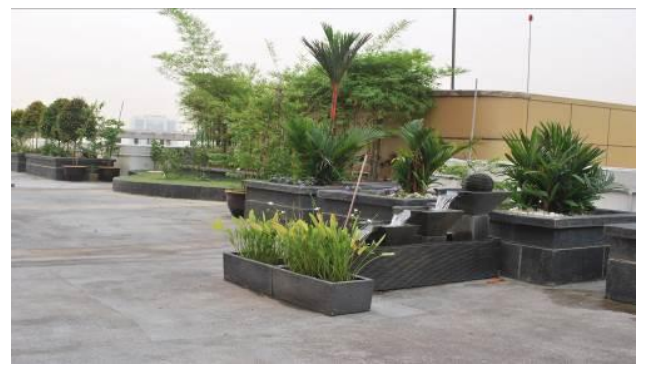

Fig. 2. (a) Pergola with wind chimes, embossed wood carvings and scented Rangoon creepers; (b) water feature and marginal plants at the TSSG

The walk-through interview results: A diverse group of end users concurred that users' accessibility, aesthetic value, maintenance, planting, the quality of sensory equipment, safety and the garden's location corresponding to the site context encouraged the garden's usage. They mentioned that having a sensory garden in hospitals, special schools, elderly care homes or in public spaces promotes sensory stimulation, physical mobility, social interaction and behavioural changes. The positive developments are significant in their recreational and sensory therapy. On the other hand, they stated a few issues when using the Garden. For example, the raised beds, reflexology pathways and water features are inaccessible for wheelchair users also lack varieties in color and textures on the pathways. Besides that, they are concern about young patients' safety when running on the hard surface and the weather conditions that limit them to stay in the garden for a longer time. They would like to see design improvements in the future.

I wish there are indications of the plant name, especially for the herbs. It would be useful for education purposes. I want to see the burst of color and smell the fragrance.

Wheelchair patient, UMMC, Kuala Lumpur (8th May 2015)

Patients with speech problem need concentration during their therapy session. The surrounding noise brings distraction for them to focus. The heat here is uncomfortable to conduct meetings.

Speech Therapist, UMMC, Kuala Lumpur (8th May 2015) 
The focus group discussion results: All practitioners concurred that they had not come across any specific guidelines for designing sensory gardens. Besides, green areas in Malaysia are often treated as a last sought out stage and left unused as dysfunctional for the users. They also often were not involved with the implementation phase, i.e. detailed design and construction stage as some clients sought to achieve cost savings. They mentioned that some owners have their in-house management and maintenance, which was asked to carry out the work directly from the master plan drawing, with no detailed drawings having been prepared. The practitioners cited that successful green spaces depend on getting the input and backing of one key group. Currently, there is no teamwork between the landscape architects, researchers, local authorities and public users.

When it comes to landscape recreational, vandalism and maintenance are issues that we have to face. Including the material used by the designers, maintenance and management of the local authority as well as the attitude of the users. We cannot change their mindset.

Landscape Architect, BAKTI-MIND (8th May 2015)

\section{Discussion and Analysis}

The data analysis results generated a question: What is it about the environment that is sensory and therapeutic? This research discovered six points, based on the evidence recorded during the observation and data findings. Good universal design practices of sensory gardens in Singapore and Hong Kong are used as guidance to assist in the analysis for the TSSG. These points are as follows:

\subsection{A continuous linkage of signage, accessible pathways and a variety of functional garden features}

All users were able to find their way back to the building, showing their cognitive ability in recognising all the information they needed in leaving the sensory garden. However, some public users were unaware of the TSSG's existence. Therefore, informative signage, continuous pathway network and circulation access to the garden, could offer easy wayfinding to the users. For regular visitors, recognisable features such as distinctively scented plants and paths with a range of colours and textures. Hence, can be used effectively as markers, thus supporting their sense of wayfinding, see Fig 3(a). Besides linking the building for easy wayfinding to the sensory garden, an accessible and even surfaced pathway can also generate activities. Here, the activities afforded users the chances to socialise or even play a game. Different surface materials, such as lawn, timber decking, chip bark and gravel could offer variety for users in stimulating their senses. However, practitioners should bear in mind that being wheeled over a rough and bumpy terrain may not always be a pleasant experience, particularly for someone with limited mobility. A variety of functional garden features positioned in strategic places, such as along pathways, offer diverse activities for recreational and sensory therapy, see Fig $3(b)$. The activities that users engaged in provided them the opportunity to experience sensorial, physical movement and social gathering.

a

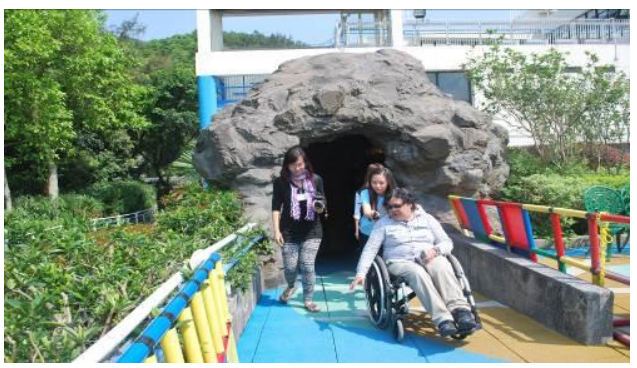

b

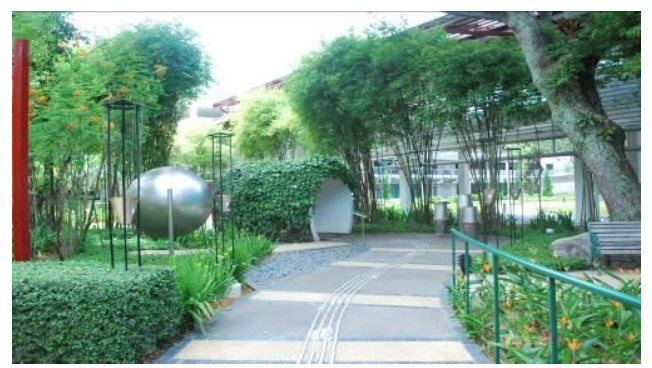

Fig. 3. (a) man-made cave with colourful wayfinding at the Haven of Hope Sunnyside School, Hong Kong; (b) example of sensory stimulation equipment placed along the pathway at BCA Academy, Singapore 


\subsection{Spatial layout and location of the garden to the site context}

In terms of the space arrangement, a sensory garden should be designed with a series of areas (possibly with themed zones), with an emphasis on making use of different senses. This method is not to say that each garden features should appeal to just one sense, but it would be a help in the initial planning stages to concentrate on each sense separately, see Fig 4. In terms of the spatial location, a sensory garden should be adjacent to the building with good access and with views from the building to the garden to encourage an outdoor therapy environment, see Fig 5. TSSG is on a higher ground and attached to one building, with an open view to Petaling Jaya. The interview results do not suggest that one on the ground is better than the upper one. Nevertheless, whatever spatial context the sensory garden has, there are other important aspects that the design professional has to consider, such as how do users access the garden from the building? How do users journey through the spaces and back to the building?

a

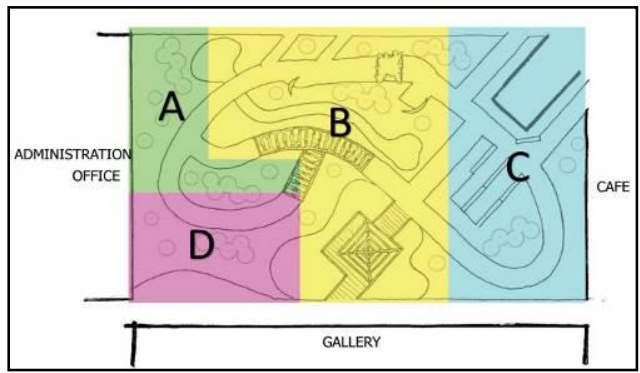

b

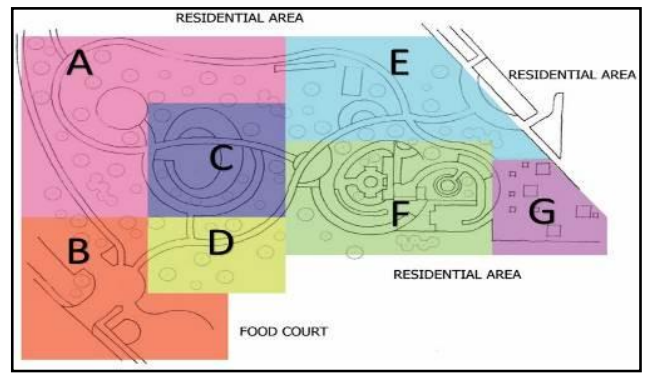

Fig. 4. (a) plan of the sensory garden at BCA Academy, Singapore. Legend: Zone A (smell), Zone B (sound), Zone C (touch), Zone D (taste); (b) plan of the sensory garden at Toa Payoh, Singapore. Legend: Zone A (community plaza), Zone B (entrance plaza), Zone C (generation activity area), Zone D (bird viewing area), Zone $\mathrm{E}$ (open space), Zone $\mathrm{F}$ (sensory garden), Zone $\mathrm{G}$ (elderly wellness station)

a

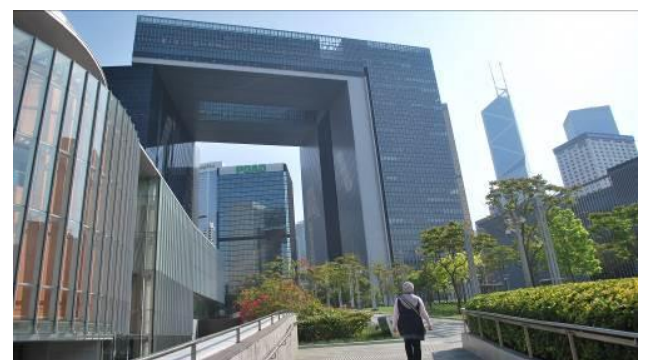

b

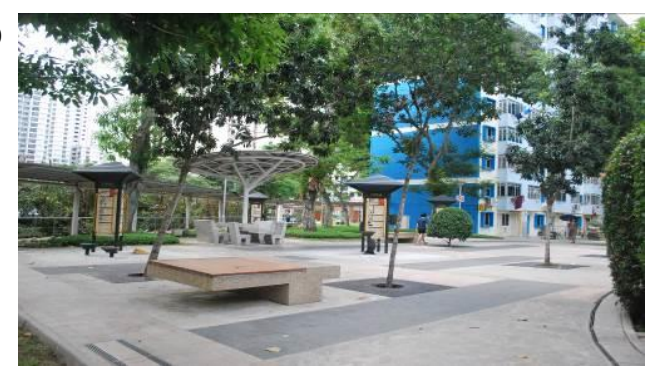

Fig. 5. (a) access green space from one building to another at HKSAR Government Building, Hong Kong; (b) centered neighbourhood park with good access from each apartment at Toa Payoh Sensory Garden, Singapore

\subsection{Garden features of hard, soft landscape, landscape furniture and wildlife refuge}

Based on the minimum and the maximum number of elements in the case study sensory gardens visited in the UK, Singapore and Hong Kong, practitioners should consider integrating four to eleven combinations of garden features. These features, which are functional in each of the themed zones, will afford various activities, for example, shelter with seating and water elements. A water fountain, a fish pond and water channel will encourage users' interest in the garden and provide opportunities for them to engage with aquatic habitats, see Fig 6(a). A composition of trees, shrubs, climbers and herbs will offer attractiveness and shade as well as harbouring wildlife in the sensory garden. Other vegetation, such as fruit trees should also be planted in the garden because they have a seasonal interest, and some produce fruits that are edible, see Fig 6(b). Besides encouraging social gathering, when it come to the harvest season, fruits trees may assist users in bringing back memories of their homes, which they have left. In contrast, plant messing with shelter and seats could afford seclusion for users to carry out their personal activities. Thus, it offers them the chance to explore further the environment. It is also sensible to provide the recommended height of not more than $600 \mathrm{~mm}$ for raised planters $(\mathrm{MS1184}, 2014)$ for wheelchair users to engage with scented plants, gardening and feel the moss growing on a wall surface while passing by. Ultimately, landscape architects should think 
about 'seasonality' when plants look their best and can be enjoyed by the users, for example, Tecoma trees (Tabebuia pentaphylla) that only blooms in March/April.

a

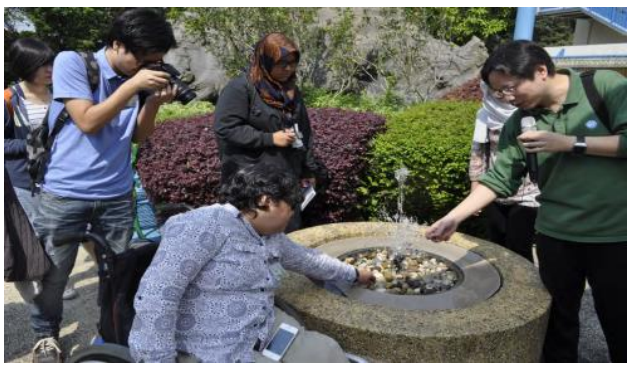

b

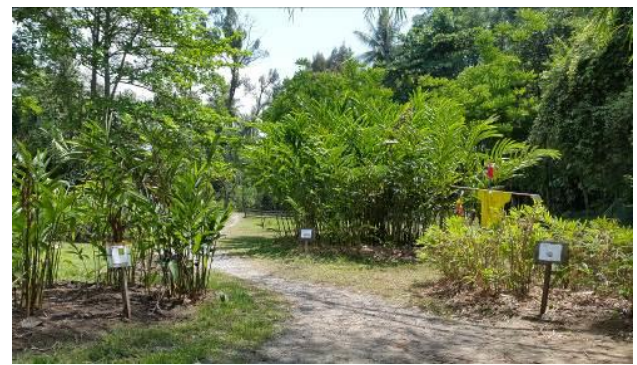

Fig. 6. (a) users engagement with water feature at the Haven of Hope Sunnyside School, Hong Kong; (b) sensory trail with variety of edible plant at Pulau Ubin, Singapore

\subsection{Microclimate and weather}

Users of the sensory garden have different reactions when engaging with the microclimate and weather. For instance, patients who are children assessed the rain as positive as it offers them the chance to splash in puddles on the pavement and to feel the rain running on their cheeks. In contrast, the therapists might assess it as negative because it makes them feeling cold and wet. By furnishing the sensory garden with a pergola and a shelter, this allows users the opportunity to experience the weather yet giving them the option either to engage with or to avoid it. Climatic factors such as sun, wind, rain and thunder also contribute to the sensory experiences that trigger users' senses. As an example, walking under a row of shady trees on a sunny afternoon might be evaluated as a comfortable ambience. In fact, a stormy weather with downpours might be rated as an undesirable situation in which to be in the natural landscape (Hussein, 2010a). Thus, allowing users the opportunity to engage with natural forces supports the link that has established between personal experiences and developing environmental cognition.

\subsection{Safety}

Sensory gardens are safer if they have enough of support staff, especially gardens that located in a public open space where there is no supervision and people are free to use them. One predictable problem that often has to resolve is the removal of branches that overhang the pathways. However, landscape architects should not take this to extremes because having something quite soft, which brushes against the skin, is sensual for users. How do landscape architects manage safety while making sensory gardens exciting and rich in experiences? Let's take a water feature, for example. Designing wheeling streams or raised pools with shallow water could draw users closer to the water. Safety is one of the design aspects that must take into account in terms of how users respond to the garden feature. In this case, it would not be by eliminating the water feature but by making it accessible and user-friendly.

\subsection{Maintenance and management}

Practitioners must consider the outdoor and indoor relationship, i.e. the quality and variety of views, as these are significant in providing interest, display and stimulation, especially through the use of detailed planting. Consideration of maintenance can avoid the overgrown plants. Thus, landscape architects must think about upkeep because there is no point in having well-designed landscapes unless they can be maintained. Plant selection and the level of maintenance need to be well thought-out. Landscape architects should translate their design intentions into a set of detailed construction drawings for the groundwork department. They should also produce a comprehensive maintenance and management schedule that would be easy to understand by the support staff or volunteers. Design consultants could also train the appointed maintenance contractors in how to maintain the sensory garden. 


\section{Conclusions and Recommendations}

Therapeutic Sensory Stimulation Garden at the University of Malaya Medical Centre, Kuala Lumpur is the first of its kind in Malaysia. As it was not originally designed to be one, its preexisting predominantly concrete features pose challenges including safety, aesthetics and access. Taking note of valuable comments by end-users and useful lessons from Hong Kong, Singapore and the United Kingdom can be further improved the therapeutic value and stimulation potential of the seven senses. A redesign should include among others, zoning, a mixture of texture and selection of flora and fauna in bright inviting and stimulating colours. The research process realizes the importance of bringing together a highly selected group of multi-professionals to deliberate and forming Therapeutic Sensory Stimulation Garden for an intergenerational society. These professional include Landscape Architect, Rehabilitation Physicians and other healthcare professionals, urban planners, policy makers, etc. To have a better Therapeutic Sensory Stimulation Garden, it should be well thought-out during the pre-planning phase of development. This consideration would allow design professionals and end users to assign space for green areas and to perceive it as a wing of a building rather than just an outdoor space. The findings had been inducing by the researchers into a subset of design considerations that will be appropriate to across all (or most) therapeutic sensory gardens. Furthermore, they will assist design professionals when they are designing for such gardens in the future. A sensory garden is highly recommended to have continuous and accessible pathways, which connects the theme zones with functional garden features and the overall site context. This recommendation is crucial in encouraging a variety of end users to engage with the characteristics placed along the pathway.

\section{Acknowledgements}

Special thanks to the University of Malaya Grand Challenge (GC001C-14SUS), Malaysian Information Network on Disabilities and all participants for making the data collection achievable.

\section{References}

Bruyere, B. (2011). Re-examining the significance of childhood reaction patterns on adult leisure behaviour. Retrieved June 2015, from Larime County: larimer.org/plugintonature/lit_review_matrix.xlsx

Chaudhury, H., Hung, L., \& Badger, M. (2013). The Role of Physical Environment in Supporting Person-centered Dining in Long-Term Care, August 2013 vol. 28 no. 5 491-500.

Detweiler, M.B., Sharma, T., \& Detweiler, J.G., Murphy, P.F., Lane, S., Carman, J., Kim, K.Y., (2012). What is the evidence to support the use of therapeutic gardens for the elderly? Psychiatry Invest.9 (2), 100-110.

Ghazali, R. \& Abbas, M.Y (2012). Assessment of Healing Environment in Paediatric Wards, Procedia - Social and Behavioural Sciences 38,149 - 159.

Harun M. T \& Salamuddin N., 2010. Cultivating personality development through outdoor education programme: the Malaysia experience. Procedia - Social and Behavioral Sciences, 9 (2010) 228-234

Hussein, H. (2009a). Therapeutic intervention: Using the sensory garden to enhance the quality of life for children with special needs. Unpublished Ph.D. thesis. Edinburgh College of Art.

Hussein, H. (2009b). Sensory gardens. Access by design (spring) Issue 118, 13-17.

Hussein, H. (2009c). Sensory garden in special schools: The issues, design and use. Journal of Design and Built Environment, 5(December), $77-95$.

Hussein, H. (2010a). Using the sensory garden as a tool to enhance the educational development and social interaction of children with special needs. British Journal of Learning Support, 25(1), 25-31.

Hussein, H. (2010b). What were, and how did, the features of the sensory garden, as engaged with by the users, influence their behavior? Procedia - Social and Behavioral Sciences, 38, 343-354.

Hussein, H. (2010c). Sensory gardens: Assessing their design and use. Intelligent Buildings International, 2(2), 116-123.

Hussein, H. (2011). The influence of sensory gardens on the behavior of children with special educational needs. Asian Journal of Environment-Behavior Studies, 2(4), 78-93.

Hussein, H., Nik Zainal Abidin, N.M. \& Omar, Z. (2013a). Engaging research and practice in creating for outdoor multi-sensory environments: Facing future challenges. Procedia - Social and Behavioral Sciences, 68, 536-546.

Hussein, H. (2013b). Patterns of seated activity in sensory gardens among children educated in special schools. Support for Learning, 28(2), $73-78$.

Hussein, H. (2015a). Sensory affordances in outdoor play environment towards well-being of special schooled children. Intelligent Buildings International, 2(2), 118.

Hussein, H. \& Daud, M.N. (2015b). Examining the methods for investigating behavioral clues of special-schooled children. Field Methods, 27(1), 97-112.

Iulian-Dorua, T., \& Maria, T., (2013). Leisure sports activities impact on adults personal development and quality of life, Procedia - Social and Behavioral Sciences 84, 1090 - 1094. 
Louv, R. (2013). Nature-deficit disorder. Retrieved 2013, from Getting Kids Outdoor: www.gettingkidsoutdoors.org/get-involved/about/nature-deficit-disorder Macoveia, S., Tufana, A. A., \& Vulpea, B. I. (2014). Theoretical Approaches to Building a Healthy Lifestyle through the Practice of Physical Activities, Procedia Social and Behavioral Sciences 117, $86-91$.

Malaysian Standard 1184 (2014). Universal design and accessibility in the built environment - Code of practice (Second revision), ICS: 25.060 .10$.

Melville, J., \& Bernard, M. (2011). Translational review of Intergenerational shared sites: Policy and practice developments in the UK. Journal of Intergenerational Relationships.

Phillips, C., \& Butler, P. (2011). Barwon Community Leadership Program 2011. Community Project Murray Howard-Brooks.

Vries, S.D. (2010). Nearby nature and human health: looking at mechanisms and their implications. In: Thompson, C.W., Aspinall, P. \& Bell, S. (Eds.), Innovative Approaches to Researching Landscape and Health: Open Space: People Space, 2. 